Perhaps the author should examine what criteria are used when cover art is selected by JAMA and make specific recommendations for evaluation. The statistics would have much more credibility if a larger base of examples (perhaps starting with the 1960s) was used, particularly if some type of trend was noticed.

The terminology of the paper could be better defined-what specifically are "stereotyped sex images"? What would be a good or healthy ratio of such stereotyped images? (The paper cites $74 \%$ of the cover art depicting humans as presenting stereotyped sex images.) I would also recommend using pejorative adjectives only when each one conveys something significant and different and can be specifically evidenced.

1 The art of JAMA. Science News Update. 1996 Oct 30.

\title{
Alliteration in medicine: a puzzling profusion of p's
}

\author{
Gregory F Hayden
}

\author{
Abstract \\ Problem Puzzling, progressive profusion of \\ alliterative "p's" in published papers. \\ Purpose To depict this particular "p" predominance \\ with pinpoint precision. \\ Plan Periodic, painstaking perusal of periodicals by a \\ professor of paediatrics. \\ Proposal The "p" plethora is positively perplexing \\ and potentially perturbing.
}

Alliteration is a literary device consisting of repetition of the same starting sound in several words in a sentence. ${ }^{1}$ Consider, for example, Shakespeare's playful parody of alliteration in Peter Quince's prologue in A Midsummer Night's Dream:

"Whereat with blade, with bloody blameful blade, He bravely broach'd his boiling bloody breast."

Alliteration has appeared frequently in the medical literature-for example: "Respiratory syncytial virusfrom chimps with colds to conundrums and cures;" "The choreas: of faints, fevers, and families;" "Coronary artery stents-gauging, gorging, and gouging;", "Moschcowitz, multimers, and metalloprotease;" "Alagille syndrome: a nutritional niche for Notch;" "Theodor Billroth: success with sutures and strings."

Perusing the medical literature with alliteration in mind, I have become perplexed by a peculiar propensity for the letter "p" to be placed in prominent positions. Consider for a moment the alliterative content of the $B M J$, a prestigious periodical also published in Pakistani, Polish, and Portuguese. Perhaps the prime example is a piece entitled "A potpourri of parasites in poetry and proverb," but the journal has presented articles addressing such topics as paracetamol poisoning, ${ }^{9}$ practitioners' pressure to prescribe, ${ }^{10}$ physicians' partnerships with patients, ${ }^{11}$ partnerships for prevention in public playgrounds, ${ }^{12}$ and pregnancy outcomes which have been persistently poor. ${ }^{13}$ Other topics have included patients' priorities,${ }^{14}$ the political process of puzzling out private versus public priorities, ${ }^{15}$ and the ponderous problem of whether the priorities in apportioning resources should be primarily pragmatic or principally principled. ${ }^{16}$

In pursuing this plethora of "p" further, it becomes apparent that this predominance extends past paper titles to many other aspects of medicine. The purpose of this paper is to point this puzzling phenomenon of "p" profusion to the attention of practising physicians.

\section{Methods}

I used no scientific search strategy but collected examples piecemeal over several years. I am a primary care paediatrician with a small private practice, so I have a natural penchant for perusing paediatric papers. Please pardon this paediatric predominance. Pathologists, pulmonologists, and other practitioners are invited to provide examples from their particular fields. I would prefer you to participate by post.

For the purposes of this paper, alliteration is defined as occurring when the same sound starts several words of a sequence. Internal alliteration is a "soundalike," whereby the same sound starts syllables within a word (for example, polyposis or parapertussis). Visual alliteration is a "lookalike," whereby successive words or syllables start with the same letter but with different sounds (for example, popliteal pterygium or pneumonic plague). This is only literally alliterative, but a pleasing abbreviation may be used, such as referring to a physician parent as a "PP." ${ }^{17}$ Non-visual alliteration occurs when successive words or syllables start with the same sound but with a different letter (for example, nosocomial pneumonia or pseudocyesis). In compiling the list of two-p sequences, I excluded: single words with internal alliteration; two-word sequences with visual alliteration; and "impure" sequences in which two "p's" were preceded, followed, or interrupted

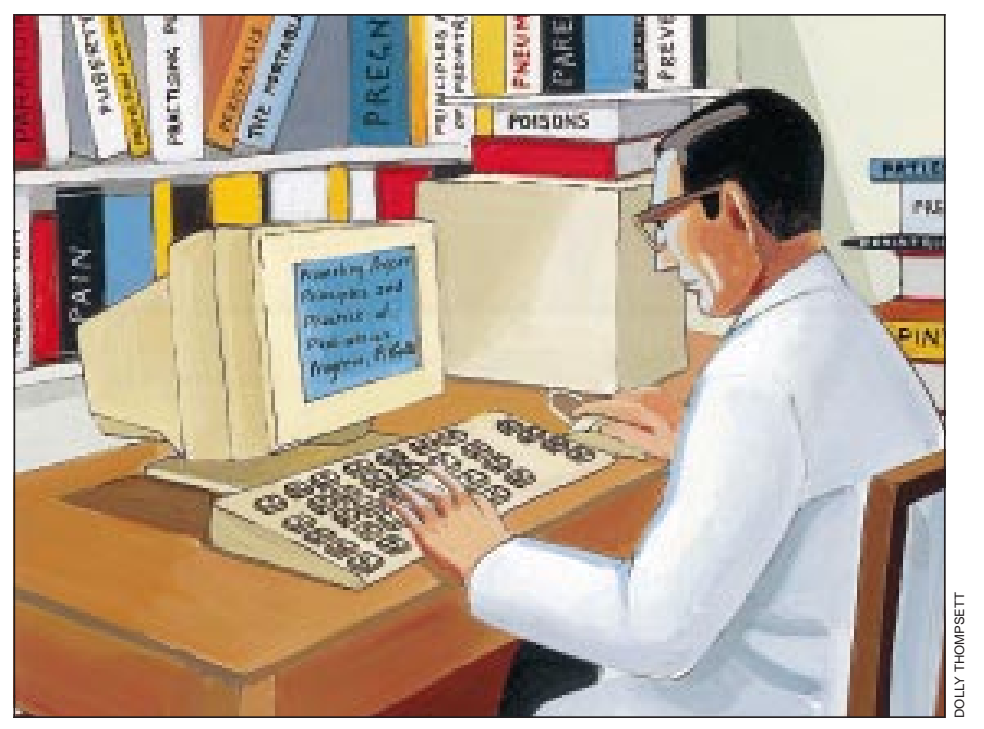




\section{Two-p sequences (in alphabetical order)}

Palmar pustules (as in neonatal candidiasis ${ }^{20}$ ) Palpable purpura (Henoch-Schönlein purpura)

Paradoxical pulse

Parakeratosa pustulosa (may include psoriatic pitting $\left.^{21}\right)$

Paralytic (or postinoculation) poliomyelitis

Parapsoriatic plaques

Passion purpura ("hickey")

Paediatric Puzzler (see text)

Paediatricians' perceptions ${ }^{22}$

Paediatrician presence ${ }^{23}$

Pediculosis pubis

Penile purpura (as manifestation of lichen

sclerosus et atrophicus ${ }^{24}$ )

Perianal pruritus (see text)

Periodic paralysis

Periodic polyserositis (familial Mediterranean fever)

Periumbilical purpura (as in disseminated strongyloidiasis ${ }^{25}$ )

Pes planus

Piezogenic papules ${ }^{26} 27$
Pink puffer

Pleuritic pain

Poison pen (see text)

Polymorphous perverse

Pool palms ${ }^{28}$ (see text)

Poor prognosis

Popsicle panniculitis ${ }^{29}$

The portable paediatrician ${ }^{30}$

(see text)

Postsurgical pemphigus ${ }^{31}$

Postural proteinuria

Practice parameter

Precocious puberty

Prolapse paranoia (mitral valve $^{32}$ )

Prone position

Prophylactic penicillin

Prurigo of pregnancy

Puffer poison (tetrodotoxin

from puffer fish)

Purulent pericarditis

Pyrantel (or pyrvinium)

pamoate (see text)

by another letter (such as PPD, the purified protein derivative used for tuberculin skin testing).

The calculation of $\mathrm{P}$ values was considered using a non-parametric procedure. The proportions of pages occupied by " $p$ " words in a general ${ }^{18}$ and medical ${ }^{19}$ dictionary are 0.07 and 0.11 , so the approximate likelihood of any particular word starting with the letter "p" (the probability of a primary $p$, expressed as $\mathrm{P}_{\mathrm{pp}}$ ) is approximately 0.09 . The precise probability of $n$ successive words starting with the letter "p" can be expressed as $\mathrm{P}_{\mathrm{pp}}^{\mathrm{n}}$

\section{Two-p sequences}

Most examples of two-p sequences are straightforward (box), but a few explanatory comments are in order.

Firstly, "pool palms" refer to palms with red linear plaques resulting from contact with rough swimming pool surfaces. ${ }^{28}$ Secondly, the presentation and proper treatment of enterobiasis are highlighted. In a paediatric patient with perianal pruritus, the prudent paediatrician should pursue the possibility of pinworms as the primary problem. If the presence of pinworms seems probable, a prescription for pyrantel pamoate or piperazine is appropriate. (Parenthetically, in years past, pyrvinium pamoate, previously patented as Povan, was another popular option.) Finally, the "paediatric puzzler" and the "poison pen" are popular features in the monthly journal Contemporary Pediatrics. One "puzzler" was entitled "A tale of two pees-pink and purple urine," ${ }^{34}$ whereas the "pen" portrays the unhappy plight of paediatric patients who experience perverse physiological phenomena after partaking of pokeweed, pot, painkillers, and other potent pharmacological agents. Parenthetically, this popular periodical recently presented one article about a Pennsylvania paediatrician who perked up his practice with a parenting programme ${ }^{35}$; a second article about an antismoking programme which proved practical for practice $^{36}$; and a third about how to put the principles of pregnancy prevention programmes into practice. $^{37}$ The journal's editor, Julia McMillan, penned The

Portable Paediatrician, ${ }^{30}$ and also an editorial entitled "Pediatrician Presence." ${ }^{23}$ The journal's creator, Frank Oski, edited the textbook Principles and Practice of Pediatrics, ${ }^{38}$ propelling us to the next level of alliteration.

\section{Three-p sequences}

Several three-p sequences have been sighted. The Pasadena Prevention Project, for example, has examined ethnic variations in blood pressures among adolescents. ${ }^{39}$ A papilloma of the bladder may cause haematuria that is profuse, periodic, and painless. ${ }^{40}$

An article on the familial aggregation of Behçet's disease studied the parents of paediatric probands. ${ }^{41}$ An editorial about death rates from coronary disease was subtitled "Progress and a Puzzling Paradox," ${ }^{, 2}$ and an article about diagnosing pulmonary embolism was subtitled "Pitfalls, Progress, Promises." ${ }^{43}$ A historical essay about William Stokes was subtitled "Stoking the fires of prevention and pathophysiological patterns," ${ }^{44}$ and a paper about substance abuse in paediatric patients was subtitled: "Prediction, Protection and Prevention." ${ }^{35}$ An article exploring the causes of paediatric behaviour problems was entitled "Promoting Parental Presence," ${ }^{46}$ and the periodical Pediatrics has recently proposed a process for post-publication peer review $\left(\mathrm{P}^{3} \mathrm{R}\right){ }^{47}$ Two recent articles pertained to substance $\mathrm{P}$ and the part it plays in pain pathogenesis. The first paper presented a procedure for the partial purification of this potent peptide,$^{48}$ whereas the second publication challenged whether the central questions in pain perception are peripheral. ${ }^{49}$

Many other three-p sequences derive from dermatological conditions. Superficial staphylococcal infections in atopic children, for example, can produce pinpoint, pruritic pustules. Recent reports have described patients with perianal pseudoverrucous papules ${ }^{50}{ }^{51}$; persistent papular plaques ${ }^{52}$; pruritic purple plaques $^{53}$; painless, pruritic papules ${ }^{54}$; persistent, painful plantar masses ${ }^{55}$; progressive, pigmentary purpura $^{56}$; pruritic papular porokeratosis ${ }^{57}$; and pedal erosions which were painful, plaque-like and pitted.$^{58} \mathrm{~A}$ final skin finding is a benign lesion of the penile corona known as pearly penile papules or pink pearly papules. $^{59}$ These lesions have occasionally been referred to as pink, pearly, penile papules, bringing us to the next level of alliteration. Parenthetically, since some parents refer to their son's penis as his "private parts" or "pee-pee," a further variation might qualify at an even higher level.

\section{Four-p sequences}

Many sequences have attained the four-p level. An editorial described "Preventive Pediatrics: the Promise and the Peril, ${ }^{, 60}$ and an article provided psychological perspectives on paediatric pain. ${ }^{61}$ Several examples derive from the dermatological literature, including: painful, piezogenic, pedal papules ${ }^{62}$; puzzling palmar and plantar papules ${ }^{63}$; porokeratosis punctata palmaris and plantaris ${ }^{64}$; and the "impure" sequence of pruritic, urticarial, papules and plaques of pregnancy (PUPPP). ${ }^{65}$ Managers of physician practice plans now apply the four p's of marketing to the medical market place: product, price, placement, and promotion. ${ }^{66}$ Finally, the internal alliteration in "A Potpourri of Parasites in Poetry and Proverb" is particularly powerful, ${ }^{8}$ pushing us to the next level. 


\section{Five-p sequences}

The five-p level of alliteration includes numerous mnemonics. The "five p's," for example, are helpful in remembering the characteristic skin lesions of lichen planus: planar, polygonal, pruritic, purple, and papular. A second five-p mnemonic describes the lesions of lichen aureus: pigmented, purpuric papules in peripheral patches. Parenthetically, these lesions are most prevalent on the periphery and carry a poor prognosis for rapid resolution. A third five-p mnemonic describes an infant with cretinism: pot belly, pallor, puffy face, protruding umbilicus, and poked out tongue. ${ }^{40} \mathrm{~A}$ fourth five-p mnemonic describes clinical features of the hands and feet of a child with acrodynia from chronic mercury poisoning: pink, puffy, painful, perspiring, and peeling. Finally, the numerous causes of paralytic ileus include five p's: postoperative, peritonitis, potassium low, pelvic and spinal fractures (plaster of Paris jacket), and parturition. ${ }^{40}$

Non-mnemonic sequences have also been noticed. The following parties are interested in measuring health outcomes: patients, providers, payers, politicians, and the public. ${ }^{67} \mathrm{~A}$ paediatric continuing education meeting was advertised as "A Potpourri of Practical Pediatrics Plus Politics," ${ }^{18}$ and a presentation at another meeting was advertised as "Presenter Promises a Potpourri of Pearls for the Practitioner." ${ }^{\prime 69}$ Patients with congenital disorders affecting multiple organ systems suffer from " $\mathrm{p} * * *$ poor protoplasm poorly put together." Once again, the internal alliteration of "potpourri" and "protoplasm" packs particular alliterative punch and propels us to still higher levels.

\section{Six-p sequences}

Peter Piper may have picked a peck of pickled peppers, but few medical sequences have attained the six-p level of alliteration. A dermatological article, however, described pruritic, pigmented papules posing permanent problems..$^{70}$ The vulgar advice offered by a high school wrestling coach also applies to medical students taking standardised examinations: "Prior preparation prevents $\mathrm{p}^{* * * *}$ poor performance." Causes of vitamin B 12 deficiency include six p's: pernicious anaemia; partial (or total) gastrectomy; pockets in bowel (diverticula or stagnant loops); parasites (Diphyllobothrium latum); pancreatitis; and paucity in diet (vegan). ${ }^{40}$ The symptoms of arterial occlusion include six p's: pallor, paraesthesia, pulselessness, paralysis, prostration, and pain. Some versions of this mnemonic also include poikilothermia, bringing us to the next level.

\section{Longer $p$ sequences}

The work of authors who have attained the highest levels of "p" alliteration deserves particular praise. In one dermatologic case report, perniotic skin lesions due to chronic cold exposure are described in a seven-p sequence as "purple patches, papules or plaques present on the proximal phalanges." ${ }^{.71}$ The complications of a Meckel's diverticulum can be remembered as the "seven p's": peptic ulceration of adjacent mucosa with melaena; perforation and general peritonitis; pain which is colicky with intussusception; pink, raspberry tumour at umbilicus; patent vitellointestinal duct; persisting band with strangulations or cysts along the track; and persistent umbilical discharge. ${ }^{40}$

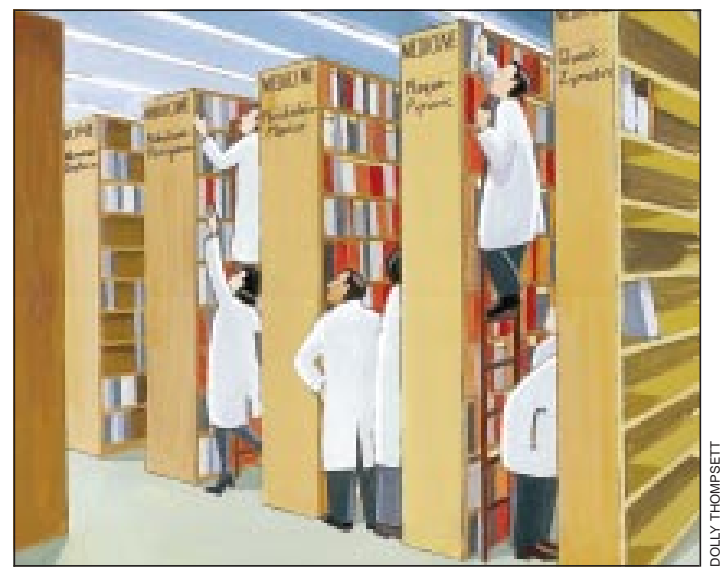

Features of primary aldosteronism include the "eight p's": periodic attacks of muscle weakness; paraesthesia; polyuria; polydipsia; potassium loss; pressure of blood rises; plasma sodium rises; and pyelonephritis likely to occur. ${ }^{40}$

In a recent article about screening for developmental delays, the authors reach the nine-p stage and urge "primary prevention through a parent professional partnership ... a proactive, primary prevention process. ${ }^{\text {.72 }}$ Features of the nephrotic syndrome include the "nine p's": proteinuria; plasma protein falls; plasma volume drops; pitting oedema with a pale, puffy face; pleural effusion; pericardial effusion; pressure of blood rises; prognosis variable; and paucity of gamma globulin lowers patient's resistance. ${ }^{40}$

One 10-p sequence is a mnemonic for the manifestations of Henoch-Schönlein (or anaphylactoid) purpura: palpable purpura; periarticular pain; periodic periumbilical pangs; proteinuria; and a positive prognosis.

Features of patients with enteric fever include "11 p's": positive blood culture early in the course; pulse slow; phlebitis; periostitis; pneumonia; parotitis; Peyer's patches ulcerated; pyonephrosis; premature delivery; perforation of bowel and blood vessels; and positive Widal reaction. ${ }^{40}$

One 12-p mnemonic includes causes of dyspnoea of rapid onset starting with "p": pneumonia, pneumothorax, pulmonary spasm (asthma), peanut (foreign body), pulmonary embolus, pericardial tamponade, pump (left heart) failure, peak seekers (high altitudes), psychogenic, poisons, pancreas (diabetes), and preand postrenal uraemia. ${ }^{40}$ This mnemonic can arguably be improved by limiting visual alliteration; pneumonia can be reclassified as pulmonary perihilar patchiness and pneumothorax as pleural pneumatic pressure. Finally, a typical patient with a perforated peptic ulcer has been described using 12 "p's" as a puking patient, perspiring with punishingly severe pain, with pulse rising, pressure falling, peristalsis losing, pain descending with pressure, guarding all over the abdomen, lying perfectly still with peritonitis. ${ }^{40}$

\section{Conclusion}

Some of my professional colleagues have perfected laboratory techniques that can be applied to a broad range of diverse topics, producing a prodigious proliferation of publishable papers. These colleagues have 
asked if I now plan 25 similar articles honouring the other letters of the alphabet. Positively not. My "p" collection has provided a pleasant pastime, but I encourage others to complete the series.

One can only ponder what the authors' possible purposes may have been for repeating " $p$ " in particular passages. In some instances, the prose is ponderous, and the "p" predominance is clearly contrived. Referring to hypertension as "pressure of blood rises," for example, was presumably done for the specific purpose of completing a long list of "p's." In other instances, however, the passages' style and polish provide pure poetic pleasure, and it seems plausible to propose that the authors were potentially unaware of their "p" proclivity and the powerful and poignant "p" presence in their papers.

Some proponents of the "publish or perish" paradigm have proposed that my primary purpose in preparing this paper for publication was a promotion. This is pure poppycock. Such a premise is perfectly preposterous. As a professor with permanence (tenure), I have reached the pinnacle of my profession. My purpose has been to pay proper and profound homage to my predecessors with a peculiar p-preoccupation. P's on earth to men of good will.

I thank Susan Hayden and Drs Margaret Mohrmann, Andy Wise, Walter Tunnessen, and Frank Saulsbury for their comments and suggestions.

1 Harris WH, Levey JS, eds. New Columbia encyclopedia. 4th ed. New York: Columbia University Press, 1975:71.

2 Hall CB, McBride JT. Respiratory syncytial virus-from chimps with colds to conundrums and cures. N Engl J Med 1991;325:57-8

3 Schoenberg DG, Schoenberg BS. The choreas: of faints, fevers and families. South Med J 1977;70:1465-6.

4 Topol EJ. Coronary artery stents-gauging, gorging and gouging. $N$ Engl JMed 1998;339:1702-4.

5 Moake JL. Moschcowitz, multimers and metalloprotease. $N$ Engl J Med 1998;339:1629-31.

6 Sokol RJ. Alagille syndrome: a nutritional niche for Notch. J Pediatr 1999;134:136-8

7 Schoenberg DG, Schoenberg BS. Theodor Billroth: success with sutures and strings. South Med J 1979;72:1590-1.

8 Burns DA. A potpourri of parasites in poetry and proverb. BMJ 1991:303:1611-4.

9 Routledge P, Vale JA, Bateman DN, Johnson GD, Jones A, Judd A, et al. Paracetamol poisoning. BMJ 1998;317:1609-10.

10 Greenhalgh G, Gill P. Pressure to prescribe. BMJ 1997;315:1482-3

11 Richards T. Partnerships with patients. BMJ 1998;316:85-6.

12 Sibert JR, Mott A, Rolfe K, James R, Evans R, Kemp A, et al. Preventing injuries in public playgrounds through partnership between health services and local authority $B M J$ 1999:318:1595.

13 Simmons D. Persistently poor pregnancy outcomes. BMJ 1997;315:263-4.

14 Richards T. Patients' priorities. BMJ 1999;318:277.

15 Klein R. Puzzling out priorities. BMJ 1998;317:959-60

16 Klein R. Priorities and rationing: pragmatism or principles? $B M J$ 1995;311:761-2.

17 Dusdieker LB, Murph JR, Murph WE, Dungy CI. Physicians treating their own children. AJDC 1993;147:146-9.

18 The Merriam-Webster dictionary. Springfield, MA: Merriam Webster, 1994.

19 Stedman's medical dictionary. 25th ed. Philadelphia, PA: Williams and Wilkins, 1990

20 Resnick SD, Greenberg RA. Auto-inoculated palmar pustules in neonatal candidiasis. Pediatr Dermatol 1989;6:206-9.

21 Tosti A, Peluso AM, Zucchelli V. Clinical features and long-term follow-up of 20 cases of parakeratosis pustulosa Pediatr Dermatol 1998:15:259-63.

22 Gray D, Golden M, Ingersoll G, Hibbard R, Langefeld C. Pediatricians'perceptions of multidisciplinary diabetes care. McLean, Virginia: Ambulatory Pediatric Association abstract, 1990

23 McMillan JA. Pediatrician presence. Contemp Pediatr 1999;16:9.

24 Barton PG, Ford MJ, Beers BB. Penile purpura as a manifestation of lichen sclerosus et atrophicus. Pediatr Dermatol 1993;10:129-31.

25 Kalb RE, Grossman ME: Periumbilical purpura in disseminated strongyloidiasis. JAMA 1986;256:1170-1

26 Van Straaten EA, Van Langen IM, Oorthuys JWE, Oosting J. Piezogenic papules of the feet in healthy children and their possible relation with connective tissue disorders. Pediatr Dermatol 1991;8:277-9.

27 Laing VB, Fleischer AB Jr. Piezogenic wrist papules. J Am Acad Dermatol 1991;24:415-7.

28 Blauvelt A, Duarte AM, Schachner LA. Pool palms. J Am Acad Dermatol 1992;27:111.
29 Craig JE, Scholz TA, Vanderhooft SL, Etheridge SP. Fat necrosis after ice application for supraventricular tachycardia termination. $J$ Pediat 1998;133:727.

30 Markel H, Oski J, Oski F, McMillan J. The portable pediatrician. St Louis, MO: Mosby Year Book, 1992

31 Mehregan DR, Roenigk RK, Gibson LE. Postsurgical pemphigus. Arch Dermatol 1992;128:414-5.

32 Kessler KM. Prolapse paranoia. J Am Coll Cardiol 1988;11:48-9.

33 Nurse DS. Prurigo of pregnancy. Aust J Dermatol 1968;9:258-67.

34 Olk DG, Glenn RE, Tunnessen WW Jr. Pediatric puzzler: A tale of two pees: pink and purple urine. Contemp Pediatr 1992;9:63-8.

35 Werner JH Jr, Mindell JA. Perking up your practice: parenting classes that work. Contemp Pediatr 1994;11:57.

36 Epps RP, Manley MW. A quick practical antismoking program for your practice. Contemp Pediatr 1994;11:24.

37 Kirby D. Reducing adolescent pregnancy: approaches that work. Contemp Pediatr 1999;16:83-94.

38 Oski FA, DeAngelis CD, Feigin RD, McMillan JA, Warshaw JB, eds. Principles and practice of pediatrics. 2nd ed. Philadelphia: Lippincott, 1994.

39 Hohn AR, Dwyer KM, Dwyer JH. Blood pressure in youth from four ethnic groups: the Pasadena Prevention Project. J Pediatr 1994;125:368-73.

40 Shipman JJ. Mnemonics and tactics in surgery and medicine. 2nd ed. Chicago: Year Book Medical Publishers, 1984

41 Kone-Paut I, Geisler I, Wechsler B, Ozen S, Ozdogan H, Rozenbaum M, et al: Familial aggregation in Behçet's disease: high frequency in siblings and parents of pediatric probands. J Pediatr 1999;135:89-93.

42 Levy D, Thom TJ. Death rates from coronary disease: progress and a puzzling paradox. N Engl J Med 1998;339:915-7.

43 Moser KM. Diagnosing pulmonary embolism: pitfalls, progress, promises. J Respir Dis 1992;13:1037-49.

44 Schoenberg DG, Schoenberg BS. William Stokes: stoking the fires of prevention and pathophysiologic patterns. South Med J 1978;71:956-7.

45 Belcher HME, Shinitzky HE. Substance abuse in children: prediction, protection and prevention. Arch Pediatr Adolesc Med 1998;152:952-60.

46 Green M. Promoting parental "presence." Contemp Pediatr 1999;16:118-38.

47 Anderson KR, Lucey JF. A new capability: postpublication peer review for Pediatrics. Pediatrics 1999;104:106.

48 Fehder WP, Ho WZ, Campbell DE, Tourtelotte WN, Michaels L, Cutilli JR, et al. Development and evaluation of a chromatographic procedure for the partial purification of substance $\mathrm{P}$ with quantitation by an enzyme immunoassay. Clin Diagnostic Lab Immunol 1998; 5:303-7.

49 Pasternak GW. The central questions in pain perception may be peripheral. Proc Natl Acad Sci USA 1998;95:10354-5.

50 Tamaki T. Diaper dermatitis and perianal pseudoverrucous papules. Arch Dermatol 1992;128:1277-80

51 Cano LR, Briones VGP, Jove RP, Rodellas AC. Perianal pseudoverrucous papules and nodules after surgery for Hirschprung's disease. I Pediatr 1994;125:914-6.

52 Fahrner LJ, Solomon AR. Persistent papular plaques on the face. Pediatr Dermatol 1989;6:254-5.

53 Yalisove BL, Berzin M, Williams CM. Multiple pruritic purple plaques. Arch Dermatol 1991;127:721.

54 Dixon TC, Meselson M, Guillemin J, Hanna PC. Anthrax. New Engl J Med 1999:341:815-26.

55 Anders KH, Lesher JL. Persistent painful plantar masses. Arch Dermatol 1992;128:105

56 Abeck D, Gross GE, Kuwert C, Steinkraus V, Mensing H, Ring J. Acetaminophen-induced progressive, pigmentary purpura (Schamberg's disease). J Am Acad Dermatol 1992;27:123-4.

57 Kanzaki T, Miwa N, Kobayashi T, Ogawa S. Eruptive pruritic papular porokeratosis. J Dermatol 1992;19:109-12.

58 Shah AS, Kamino H, Prose NS. Painful, plaque-like pitted keratolysis occurring in childhood. Pediatr Dermatol 1992;9:251-4.

59 Neinstein L Goldenring J. Pink pearly papules: an epidemiologic study. $J$ Pediatr 1984;105:594-5.

60 Eisenberg L. Preventive pediatrics; the promise and the peril. Pediatrics 1987;80:415-22.

61 McGrath PJ, McAlpine L. Psychologic perspectives on pediatric pain. $J$ Pediatr 1993;122:S2-S8

62 Kahana M, Levy A, Ronnen M, Cohen M, Schewach-Millet M. Painful piezogenic pedal papules on a child with Ehlers-Danlos syndrome. Pediatr Dermatol 1985;3:45-7.

63 Solis J, Sau P, James WD. Puzzling palmar and plantar papules. Arch Dermatol 1991;127:1219-24.

64 Lestringant GG, Berge T. Porokeratosis punctata palmaris and plantaris: A new entity? Arch Dermatol 1989;125:816-9.

65 Weiss R, Hull P. Pruritic, urticarial, papules and plaques of pregnancy. $J$ Am Acad Dermatol 1992;26:715-7.

66 Maibach E. Communication strategies for expanding and sustaining immunization. Children's Vaccine Initiative Consultative Group Meeting; Geneva, Switzerland, November 1998. Geneva: World Health Organisation, 1998

67 Detsky AS, Redelmeier DA. Measuring health outcomes: putting gains into perspective. $N$ Engl J Med 1998;339:402-3.

68 Virginia Chapter of the American Academy of Pediatrics. A potpourri of practical pediatrics plus politics. Virginia Pediatrics [the Chapter newsletter], Summer 1994.

69 American Academy of Pediatrics. Presenter promises potpourri of pearls for the practitioner. Elk Grove Village, Illinois: AAP Highlight, April 1994:1.

70 Gebauer KA, Navaratnam TE, Holgate C. Pruritic, pigmented papules posing permanent problems. Arch Dermatol 1992;128:105.

71 White KP, Rothe MJ, Milanese A, Grant-Kels JM. Perniosis in association with anorexia nervosa. Pediatr Dermatol 1994;11:1-5.

72 Frankenburg WK. Preventing developmental delays: is developmental screening sufficient? Pediatrics 1994;93:586-93. 